\title{
CULTURA E IDENTIDADES JUVENILES
}

JUAREZ DAYRELL *

\section{INTRODUCCIÓN}

EN ESTE ARTÍCULO TRATAMOS del joven que hace parte de grupos musicales, específicamente de los «rappers y funkeiros». Entretanto la discusión no será sobre los estilos rap y funk en sí mismos, lo que ya fuera discutido en artículos anteriores. ${ }^{1}$ Aquí proponemos una mirada sobre los jóvenes además de los grupos musicales, intentando comprenderlos como sujetos sociales, que como tales, construyen una determinada forma de ser joven. Es decir, estamos preguntándonos sobre quiénes son estos jóvenes que participan de grupos de rap y funk.

Tras analizar la producción teórica sobre grupos musicales juveniles en Brasil, por lo menos aquellas que tuvimos acceso, ${ }^{2}$ percibimos una tendencia en la descripción y análisis en sí mismos (de los jóvenes que forman los grupos), permitiendo el conocimiento de su realidad cotidiana, cómo construyen el estilo, los significados que le atribuyen y lo que expresan en el contexto de una sociedad cada vez más globalizada. Estos estudios mucho contribuyeron para problema-

* $\quad$ Profesor de la Facultad de Educación de la Universidad Federal de Minas Gerais, Belo Horizonte, Brasil. E-Mail: juarezd@uai.com.br.

Traducción de Emilia Cassia Ribeiro Silva.

$1 \quad$ Ver Dayrell (1999, 2002a y 2002b).

2 Ver Dayrell (1999, 2002a y 2002b); Guimarães (1995); Andrade (1996); Cechetto (1997); Silva (1998); Arce (1999); Herschmann (2000); Tella (2000). 
tizar la cultura juvenil contemporánea, exponiendo por medio de ella, los deseos y problemas vividos por la juventud brasileña.

Entretanto, a pesar de sus contribuciones, esta producción teórica presenta un hueco. Tras construir su objeto, tales investigaciones recortan de tal forma la realidad de los jóvenes que casi impide su visión como sujetos, en su totalidad. Podemos conocer el joven como un 'raper o un funkeiro', pero sabemos muy poco respeto de esa identidad en el conjunto que, seguramente hace que él sea lo que es en aquel momento.

Por otra parte, nos paramos en el cotidiano con una serie de imágenes respecto de la juventud que interfieren en nuestra manera de comprenderlos. Una de las más fuertes, es la juventud vista en su condición de transitoriedad, donde el joven es un «venir a ser», teniendo en el futuro, el pasaje para la vida adulta, el sentido de sus acciones, lo que aún no logró ser (Salem, 1986), negando el presente vivido. Esa concepción está muy presente en la escuela, en nombre del «venir a ser» del alumno, expreso en el certificado y en los posibles proyectos futuros, tendiendo a negar el presente del joven como espacio válido de formación, así como las questiones existenciales que ellos exponen, mucho más amplias que apenas el futuro.

Otra imagen presente es la visión romántica del joven que vino a ser cristalizando desde los años sesenta, resultado, entre otros, del surgimiento de la industria de consumo dirigida a los jóvenes, que se tradujo en adornos, modas, locales para diversión, músicas, revistas, etc. (Feixa, 1998; Leccardi, 1991; Abramo, 1994).

En esa visión la juventud sería un tiempo de libertad, de placer, de expresión, de comportamientos raros. A ese pensamiento se junta la idea de moratoria, como un tiempo para el ensayo y el error, para las experimentaciones, un período marcado por el hedonismo y por la irresponsabilidad, con una relativización de la aplicación de sanciones sobre el comportamiento juvenil.

Más recientemente, se añade otra tendencia en percibir el joven reducido apenas al campo de la cultura, como si él sólo expresase su condición juvenil en los fines de semana o cuando participa de o en actividades culturales.

Esas imagines conviven con otra; la juventud vista como un momento de crisis, una fase difícil, dominada por conflictos con su autoestima y o su personalidad. Unido a esa idea existe una tendencia en considerar la juventud como una época de alejamiento de la familia, apuntando para una posible crisis en la familia como institución 
socializadora. Algunos autores vienen resaltando que la familia, juntamente con el trabajo y la escuela, estaría perdiendo su papel central de orientación y de valores para las generaciones más jóvenes (Morcellini, 1997; Abromavay, 1999; Zaluar, 1997).

Es necesario poner en questión esas imágenes pues, cuando arraigados en esos modelos socialmente construidos, corremos el riesgo de analizar los jóvenes de forma negativa, enfatizando las características que le faltarían para corresponder a un determinado modelo de «ser joven». De esa forma coseguimos comprender cómo los jóvenes reales, principalmente los de camadas populares, construyen su experiencia.

Delante de tales preocupaciones, pretendemos evidenciar en este artículo, cómo los jóvenes, mientras sujetos sociales, construyen un determinado modo de ser joven, a partir de su cotidiano. Para eso tomaremos como foco jóvenes de las camadas populares pertenecientes a grupos musicales en este caso, el 'rap y funk'. ${ }^{3}$

¿Quiénes son estos jóvenes fuera de los grupos de los cuales participan?, ¿cómo construyen un determinado modo de ser joven en su cotidiano? Para desarrollar tales questionamientos, es necesario explicar nuestra mirada sobre la juventud, así como nuestra comprensión del joven como sujeto social. Iniciemos pues por esa discusión.

\section{2. ¿ ¿JUVENTUD? JUVENTUDES...}

Construir una definición de la categoría de la juventud no es fácil, principalmente porque los criterios que la constituyen son históricos y culturales. Muchos autores ya investigaron sobre el tema, trayendo importantes contribuciones, no siendo nuestro propósito aquí recuperar toda esa discusión. ${ }^{4}$ En este artículo, nos limitaremos a explicitar nuestra posición, resaltando la dimensión de la diversidad presente en la misma.

Así como Peralva (1997), comprendemos que la juventud es, al mismo tiempo, una condición social y un tipo de representación. Si hay un carácter universal dado por las transformaciones del individuo en una determinada franja etárea, en las cuales completa su desarrollo

3 Los datos empíricos son parte de la investigación que resultó en la Tesis de Doctorado de nombre: «La música entra en escena: el rap y el funk en la socialización de la juventud en Belo Horizonte».

$4 \quad$ Para una discusión más profundizada sobre la noción de la juventud, ver Feixa (1998); Dayrell (1999, 2001); Pais (1993); Sposito (1993 y 2000). 
físico y enfrenta cambios psicológicos, es muy variada la forma como cada sociedad va a reaccionar en ese momento. Esa diversidad se concretiza en las condiciones sociales (clases sociales), culturales (etnias, identidades religiosas, valores), de género y también de las regiones geográficas, entre otros aspectos.

Construir una noción de juventud en la óptica de la diversidad implica, en primer lugar, considerarla no más presa a criterios rígidos, sino como parte de un proceso de crecimiento más totalizante, que adquiere contornos específicos en el conjunto de las experiencias vividas por los individuos en su contexto social. Significa no entender la juventud como una etapa con un fin predeterminado, tampoco como un momento de preparación que será superado cuando este joven ingresar en la vida adulta.

En esa línea de pensamiento, Melucci (1992) nos propone otra forma de comprender la adolescencia y la juventud. Para él existe una secuencia temporal en el curso de la vida, cuya naturidad biológica hace surgir determinadas potencialidades. En ese sentido es posible determinar el inicio de la juventud, cuando físicamente se adiquiere el poder de procrear, cuando la persona presenta señales de necesitar de menos protección familiar, cuando empieza a asumir responsabilidades, a buscar independencia y a ofrecer pruebas de auto-suficiencia; así como otras señales corporales y psicológicas. Con todo, para el autor, una secuencia temporal no implica necesariamente una evolución lineal, en la que ocurre una complejidad cresciente, como la sustitución de las fases primitivas por las fases más maduras, de tal forma de cancelar las experiencias anteriores.

Melucci, al revés, defiende la idea que los fenómenos evolutivos presentes en los cambios de los ciclos vitales son hechos que dicen respecto a cada momento de la existencia, haciendo de los cambios o transformaciones una característica estable de la vida del individuo. Así la adolescencia no puede se entendida como un tiempo que termina, como una etapa de la crisis o de pasaje entre la infancia y la vida adulta, entendida como punto último de la madurez. Sino que representa el momento del comienzo de la juventud, momento éste cuyo punto central es constituido por cambios corporales, afectivos, de referencias sociales y de relacionamentos. Un momento en el que se vive, de forma más intensa, un conjunto de transformaciones que estarán presentes de alguna forma a lo largo de la vida.

De esa discusión entendemos la juventud como parte de un proceso más amplio de constitución de sujetos, pero que tiene sus 
especificidades que marcan la vida de cada uno. La juventud constituye un momento determinado, pero no se reduce a un pasaje, asumiendo una importancia en sí misma. Todo ese proceso es influenciado por el medio social concreto en el que el joven se desarrolla y por la cualidad de los cambios que éste proporciona. Así los jóvenes investigados construyen determinados modos de ser joven que presentan especificidades, lo que no significa que haya un único modo de ser joven en las camadas populares. Es en ese sentido que enfatizaremos la noción de juventudes, en plural, para destacar la diversidad de los modos de ser joven. Así comprendida, se torna necesario articular la noción de juventud a la de sujeto social.

\section{LOS JÓVENES COMO SUJETOS SOCIALES}

Generalmente la noción de sujeto social es tomada con un sentido en sí misma, sin la preocupación en definirla, como si fuera consensual a la comprensión de su significado. Otras veces es tomada como sinónimo de individuo o aun como actor social. Para algunos, hablar de «sujeto» implica una condición que se logra con la definición de algunos pre-requisitos para tal; para otros, es una condición ontológica, propia del ser humano. En los límites de este artículo, no cabe una discusión que recupere la construcción del concepto, y nos limitaremos a asumir determinada opción.

Para efectos de nuestro análisis asumimos la definición de Charlot (2000:33, 51), para quien el sujeto es un ser humano abierto a un mundo que posee una historicidad, portador de deseos y movido por esos deseos, en relación a otros seres humanos, ellos también son sujetos. Al mismo tiempo, el sujeto es también un ser social, con un determinado origen familiar, que ocupa un determinado lugar social y se encuentra inserto en relaciones sociales. Finalmente, el sujeto es un ser singular, que tiene una historia, que interpreta el mundo dándole sentido, así como a la posición que ocupa en él, a sus relaciones con los demás, a su propia historia y su singularidad. Para el autor, el sujeto es un ser activo, que actúa en y sobre el mundo, y en esa acción se produce al mismo tiempo que es producido el conjunto de las relaciones sociales en la que se inserta.

Charlot relaciona la noción de sujeto a las características que definen la propia condición antropológica que constituye el ser humano, es decir, el ser humano no es uno dado, sino una construcción. La condición humana es vista como un proceso, un constante 
tornarse por sí mismo, en el que se constituye como sujeto mientras se constituye como ser humano con el desarrollo de las potencialidades que le caracterizan como especie. Y un desarrollo que no está dado, pasando a desarrollar otra fase de la condición humana, que es su naturaleza social. Charlot (2000:52), nos acuerda que la esencia originaria del ser humano no está dentro de él mismo, sino fuera, en una posición excéntrica en el mundo de las relaciones sociales. Decir que esta posición excéntrica es antes de todo social, es lo mismo que afirmar que el hombre se constituye en la relación con el otro.

Al mismo tiempo, la alteridad, vista en esta perspectiva, muestra que el ser humano se pone en el límite entre la naturaleza y la cultura, en la que la dimensión biológica y la social se mezclan en la producción humana. La posibilidad del ser humano de constituirse como tal, depende tanto de su desarrollo biológico, en especial del sistema nervioso, así como de la calidad de los cambio que ocurren entre los hombres en el medio en que está inserto.

Podemos concluir que el pleno desarrollo o no de las potencialidades que caracterizan el ser humano, dependerá de las realciones sociales del medio en el que está inserto. De esa forma estamos de acuerdo con Charlot cuando afirma que todo ser humno es sujeto. Pero es necesario llevar en consideración que existen varias maneras de construirse como sujeto, y una de ellas se refiere a los contextos de deshumanización, en los que el ser humano es "prohibido de ser», es privado de desarrollar sus potencialidades, de vivir plenamente su condición humana, como nos será posible constatar en la mayoría de los jóvenes investigados. No es que ellos no se construyan como sujetos, o lo hagan por la mitad, sino que ellos se construyen como tales de acuerdo con los recurso que poseen. Es esa realidad que nos lleva a preguntar si esos jóvenes no estarían mostrándonos una forma propia de vivir.

Cuando cada uno de esos jóvenes nació, la sociedad ya existía y su estructura no dependió de ese sujeto, por lo tanto no fue producida por él. Así, el género, la raza, el hecho que sus padres sean trabajadores descalificados, la mayoría con poca escolaridad, entre otros aspectos, son dimensiones que interfirieron en la producción de cada uno de ellos como sujetos sociales, independientemente de la acción de cada uno. Al mismo tiempo, en la vida cotidiana, entra en un conjunto de relaciones y procesos que constituyen un sistema de sentido, que dice quién es él, quién es el mundo y quiénes son los demás. Es el nivel del grupo social, en el que los individuos se identifican por las 
formas propias de vivenciar e interpretar las relaciones y contradicciones entre sí y con la sociedad, lo que produce una cultura propia.

Nuestro contacto con los jóvenes investigados deja claro lo aparentemente óbvio: ellos son seres humanos, aman, sufren, se divierten, piensan sobre sus condiciones, sus experiencias de vida, se posicionan frente ella, poseen deseos y propuestas para mejoría de su vida. Creemos que es en ese proceso que cada uno de ellos va siendo construido y se construye como sujeto, un ser singular que se apropia del social, transformado en representaciones, aspiraciones y prácticas, que interpreta y da sentido a su mundo y a las relaciones que mantiene.

Mirar los jóvenes como sujetos no se reduce a una opción teórica, eso dice respecto a un postura metodológica y ética no sólo durante el proceso de investigación, sino también en nuestro cotidiano como educadores. La invetigación nos mostró que ver e interactuar con el joven como sujeto, capaz de reflejar, de tener sus propias posiciones y acciones es un aprendizaje que exige esfuerzo de autoreflexión, lejanía y autocrítica. La dificultad es aún mayor cuando el otro es «joven, negro y pobre», esa tríada que sigue junto a muchos jóvenes como una maldición. De esa misma forma, creemos que este artículo no habla «de jóvenes», sino de los jóvenes en su relación con el investigador, y al revés. Es resultado de una forma de observar que es centrado en las relaciones. Significa decir que los jóvenes no son apenas objeto de la observación, sino que son personas en relación con aquel que observa. Tenemos claro que construimos un texto que se refiere a hechos socialmente construidos, con la consciencia de la lejanía que separa la interpretación de la «realidad».

\section{LOS SUJETOS DE LA INVESTIGACIÓN}

Para desarrollar esta investigación elegimos dos jóvenes que serán los hilos conductores del análisis: 'João' es un raper; 'Flavinho' es un funkeiro. ${ }^{5}$ No tenemos el propósito de tratarlos como modelos. Ellos son sujetos concretos, con experiencias singulares, cuyas trayectorias de vida pueden ofrecer elementos para mejor comprenderlos,

5 La elección de esos jóvenes ocurrió en la última fase de la investigación, después de una serie de pasos metodológicos, entre ellos la realización de una investigación telefónica con 146 grupos musicales juveniles, y la selección de 6 grupos de rap y funk. Con esos dos jóvenes, tuvimos contactos intensos, además de entrevistas más profundas. Para mayores detalles, ver Dayrell, 2001. 
además de la identidad como rappers o funkeiros. Los dos jóvenes expresan experiencias y momentos de vida diferenciados, revelando mundos propios.

a) João y el rap

João es un rapper, integrante del grupo Máscara Negra, tiene 22 años, es negro y vive con su madre y un hermano. La madre trabajaba como cocinera en bares y casas de familia, pero actualmente está jubilada por motivos de salud. La sobrevivencia de la familia es garantizada por la contribución de todos sus miembros, aunque João es el que menos contribuye, eso para que pueda invertir en su carrera musical. Eso muestra que su familia ve en la música, el rap, una carrera posible.

João considera que las relaciones familiares son muy importantes para su vida: «eu gosto da minha mãe e do meu irmão prá caralho...». ${ }^{6}$ Siempre que él se refiere a su madre o a su hermano, lo hace con admiración, dejando claro la importancia de ellos en su formación. João enfatiza la importancia actual de la práctica del diálogo y de las negociaciones en el interior de la familia en su madurez. Diferente del clima de conflictos constantes años antes, cuando era menor.

Agora lá em casa sempre rolou muita conversa. Sempre foi tudo aberto, assunto de sexo, assunto de música, tudo rola, até assunto de televisão Acho que é isso que me ajudou a não ter um filho até hoje, essa história de naõ ter feito muita treta (malandragem). A gente sempre fala aberto... ${ }^{7}$

João trabaja desde los13 años, en los más distintos 'bicos' (trabajos informales), y actualemente es ayudante de herrero. Durante el tiempo en que lo acompañamos, él no tenía empleo fijo, ocupando buena parte de su tiempo buscando trabajo en las herrerías de su barrio para intentar encontrar algo para hacer, por lo que recibía $\mathrm{R} \$ 10,00$ (10 reales) por día. Él no se siente un profesional en la ocupación que ejerce, tampoco le gusta lo que hace:

$6 \quad$...Me gusta muchísimo mi madre y hermano...

7 Ahora allá en mi casa siempre hay mucho diálogo. Siempre fue todo abierto, temas como sexo, música, hay de todo, hasta temas sobre la tele. Creo que eso es lo que me ayudó a no tener un hijo hasta hoy, esa historia de no haber hecho tonterías (cosas malas). Siempre hablamos sobre todo... 
[A serralheria] é um trampo que eu mais detesto, cara! Se ocê soubesse o quê que é queimar o olho na solda:; o quê que é ficar sem dormir por causa das vista queimada. Eu vou te falar, é brabo... 8

En sus experiencias en el mundo del trabajo no estuvo y no está presente la dimensión de la escuela, ya que el trabajo es una obligación necesaria. João convive con la dificultad en conciliar el tiempo entre el trabajo y sus actividades musicales, una vez que aquél disminuye las posibilidades de invertir en la música, que es lo que más le gusta y lo hace sentirse productivo. Comentando sobre uno de los pocos empleos fijos que ya tuvo, João se acuerda:

Chegava dentro da firma e minha cabeça num era para aquilo lá, trabalhei em muitos lugarea, cara, mas minha cabeça num aceitava... era aquele trauma, ficava nervoso porque eu pensava: Pô eu tenho de fazer é música, omeu negócio é aquilo á, é só com isso que eu me entretenho, é nisso que eu tenho uma vontade, cara! ${ }^{9}$

El gran sueño de João es sobrevivir de la música o por lo menos de alguna actividad relacionada a ella y o al mundo de la cultura. Él fue excluido del mundo de la escuela en el quinto año de la enseñanza fundamental, no volviendo a estudiar desde entonces. La escuela es recordada como un espacio que no le seducía, ya que estaba lejana de sus intereses y necesidades («a escola não me cativava, nãome despertava interesse, era um saco... aí eu fui desinteressabdo pelo estudo...»). ${ }^{10}$ Se acuerda con amargura de las tres reprobaciones sufridas; de su imagen de mal alumno, siempre relacionado con peleas y discusiones con los profesores. Según él, la única buena recordación que tenía era de una profesora que envió una comunicación a su madre diciendo que,

eu era carente e que eu precisava de carinho. Que eu não era tão moleque como minha mãe imaginava. Depois disso, nó fiquei na maior empolgação com ela, eu até me apaixonei por ela ella. ${ }^{11}$

$8 \quad$ ¡Hombre! ¡La herrería es un trabajo que no me gusta para nada! Si supieras lo que es quemar el ojo con la soldadura; lo que es quedar sin dormir debido a los ojos quemados. Voy a decirte, es terrible...

9 Llegaba a la empresa y mi cabeza no estaba allí. Hombre, trabajé en muchos lugares, pero mi cabeza no aceptaba... era muy difícil, me quedaba nervioso porque pensaba: Lo que debo hacer es la música, mi negocio es ése, y es sólo con eso que me siento bien, es lo que tengo ganas de hacer...

10 La escuela no me cautivaba, no me despertaba interés, era una lata... entonces me fui desinteresando por los estudios...

11 'Yo' era carente y que precisaba de cariño. Que ‘yo’ no era pícaro como mi 
Además de eso había la necesidad de y el deseo de trabajar, que atendiera las necesidades de consumo y de diversión. Actualmente, João reconoce que la falta de un certificado disminuye sus posibilidades en el mercado de trabajo y se dice arrepentido por no haber concluido la enseñanza básica (hasta el octavo año de estudios), lo que contribuye a disminuir su autoestima.

El contexto en el que João viene siendo socializado, el 'hip hop', y específicamente el rap, cumplió y aún cumple un papel significante en su vida. Él vino construyendo su vida, su red de relaciones y sus proyectos alrededor de su estilo, lo que mucho interfirió en la forma como se presentaba, en la visión de mundo que posee, en los comportamientos y valores que expresa, constituyéndose en un estilo de vida.

João adhirió al hip hop desde la adolescencia, inicialmente participando de grupos de 'break' con quienes frecuentaba los 'bailes' (clubes) además de participar de las competiciones donde vivía. De acuerdo con él, la adhesión al hip hop contribuyó en la mejoría de su gusto musical y en el descubrimiento de sus potencialidades artísticas como productor musical y cantante. Mientras tanto le posibilitó una ampliación del dominio del espacio urbano además de su barrio, pues pasó a frecuentar fiestas en diferentes regiones de la ciudad, aumentando así su propia red de relaciones.

Com o hip hop passei a andar para tudo quanto é lado. Onde que achava que tinha alguma coisa a gente ia. Num tinha limites não; tem uma festa em tal lugar? Rola? Vamo embora: bairro São Paulo, bairro Nacional, Industrial, no Eldorado, tudo que é canto... ${ }^{12}$

En 1995 João formó el grupo Máscara Negra junto con tres amigos, con los cuales actúa hasta hoy. Ellos se presentan en fiestas de calle y eventos de hip hop, teniendo una cierta proyección en el medio.

João se encuentra con el grupo con mucha regularidad, quedándose juntos prácticamente todas las noches para los entrenos, producción de músicas o para salir juntos. Él admite que ya tuvieron y aún hay algunos desentendimientos entre ellos, pero aprendieron a convivir con las diferencias, mejorando las relaciones entre ellos. La

madre se lo imaginaba. Después de eso, por Dios sólo me encantaba con ella, creo que hasta me apasioné por ella.

12 Con el hip hop empecé a andar por muchos lugares. Donde creía que ocurría algo, nosotros íbamos. No había límites, ¿hay una fiesta en tal lugar? Allí íbamos nosotros, cualquier barrio, ahí estábamos. 
amistad y los intereses comunes hacen del grupo una referencia importante para cada uno de ellos. João enfatiza las relaciones de confianza existentes: «pueden contar unos con los otros, cambiando ideas sobre la vida personal y afectiva», siendo un locus de construcción de una identidad colectiva, pero también individual. Otro punto de referencia con la que João cuenta es la novia, en una relación valorada por lo que significa de afirmación y estímulo para enfrentar las dificultades y realizar sus proyectos. Para João, su noviazgo es uno de los puntos que lo llevan a la transición por el mundo adulto, interfiriendo en sus opciones.

Otra referencia un poco menos importante, son los colegas, casi todos participantes del movimiento hip hop, con los que se encuentra en los momentos de diversión. João ya se encuentra con los dilemas típicos de la transición para la vida adulta, él mismo se considera un joven adulto. El aumento de las responsabilidades en casa y el propio noviazgo son señales de ese momento;

Hoje eu tô preocupado em arrumar outras coisas, eu tenho noiva, que vem coisa séria, vem o grupo, ocê passa a olhar mesmo a situação sua dentro de csa e tudo. Aí ocêpassa a ficar um pouco mais sério ocê entendeu? Hoje em dia meus amigos é pouco, porque; assim, meus amigos foi muito de zuera, né, e vai acabando esses tipo de amizade assim de zuera. Nem todo mundo tem esse processo, mas eu tive. Ocê fica mais sério, a gente vai ficando adulto, né véio... 13

En el momento de la investigación, João estaba repensando su opción por la música, cuestionándose sobre las opciones realizadas hasta entonces y las perspectivas de futuro. En este contexto, él expresa una cierta representación socialmente construida del adulto, presente en el medio popular, que presenta algunas polaridades en relación al joven como: serio $\mathrm{X}$ burlador; responsable $\mathrm{X}$ irresponsable. Frente a esa imagen, hay la exigencia de una nueva postura. Si antes lo que le movía era la diversión, hoy él exige de sí mismo mayor seriedad. El grupo de amigos disminuye, fruto de un proceso de

13 Hoy estoy preocupado en arreglar otras cosas, yo tengo novia, viene ahí cosa seria; viene el grupo... Uno pasa a mirar su situación dentro de casa y todo... Entoces tú te tornas un poco más serio, ¿entiendes? Hoy día mis amigos son pocos, porque mis amigos eran casi todos para juegos, ¿sabes? Y esto se va terminando, ese tipo de amistad sólo para juegos y tonterías... No todos tienen ese proceso que tuve. Uno se queda más serio, se va tornando más adulto, ¿verdad? 
selección. Esta postura se concretiza en la división del tiempo, en la elección de los programas con los que ocupa su tiempo libre. En esa época, los fines de semana son ocupados principalmente con el noviazgo, con la novia acompañándole a los shows en los que el grupo se presentaba. Además de eso, solía frecuentar bares y fiestas de hip hop, siempre con los amigos más cercanos, pero no dejaba de 'dar un rolé' (ir) a los bares o 'rodas de samba', pues le gustaba demasiado.

Podemos constatar que en el contexto en el que João vino construyéndose, el rap fue, y aún es, uno de los pocos espacios, además de la familia, en el que encuentra apoyo, donde puede establecer cambios, donde puede elaborar proyectos que dan sentido a su vida en el presente. En aquel momento, él elaboraba un proyecto de vida:

Meu trabalho é a música e o trampo que ela gera... É isso que eu quero, ser respeitado dentro do campo musical... Eu quero conseguir um poder aquisitivo, unm financeir melhor, isso é lógico, quem viveu a vida inteira na pobreza é lógico que quer subir na vida... resumindo é isso aí mesmo. Coisa simples, no mais, quero casar, é lógico... sou noivo, é minha idade né? E ver minha mãe melhor, esses trens assim. Dar à minha mãe o que ela não teve, coisas assim, todo mundo pensa. ${ }^{14}$

Lo que João expresa por intermedio del rap es el deseo de realizarse. Eso es, ser un artista profesional, ser respetado como creador musical, tener una vida digna para sí mismo y para su familia. Todo muy simple y al mismo tiempo tan lejos, como él dice.

\section{b) Flavinho: un funkeiro inmerso en el presente}

Flavinho tiene 19 años, es un chico blanco y es un funkeiro que forma una pareja con su amigo Leo. Aquél es un ejemplo del joven que vive plenamente su condición juvenil, con tiempo libre para dedicarse al funk, a los amigos y a su novia. Es el hijo menor de cuatro hermanos, que viven con la madre, una operaria textil. Poseen casa propia, en un 'conjunto habitacional', 15 en las afueras de Belo Horizonte. Su padre dejó la casa hace siete años y desde entonces Flavinho

14 Mi trabajo es la música y el trabajo que ella genera... Es eso que quiero, ser respetado dentro del campo musical... Quiero conseguir un poder financiero mejor, eso es lógico. Quien vivió la vida entera en la pobreza, es lógico que quiera subir en la vida... resumiendo; eso. Cosa simple, además, quiero casarme, es lógico... soy novio, es mi edad ¿verdad? Y ver a mi madre mejor, esas cosas así. Dar a mi madre lo que ella no tuvo, cosas así que todos piensan. 
nunca más volvió a verlo. Así como los demás entrevistados, Flavinho dice tener un bueno relacionamiento con su madre, con quien dice charlar más. Pero cuando compara su familia con la de sus amigos, la considera más cerrada:

Eu acho que aqui em casa o pessoal é mais fechado, né. Não sou de conversar com eles [os irmãos], sou de conversar mais com minha mãe... Mas minha mãe não conversa, nem eu procuro conversar com ela sobre sexo ou drogas, por exemplo... Eu acho que a família de outros amigos são mais assim, Relacionadas com eles... Eu acho isso legal... em certos pontos a família deles é mais legal que a minha... ${ }^{16}$

Para Flavinho la familia no es donde pueda hablar sobre los problemas y dudas propios de la fase que vive, como de la sexualidad y las drogas. Esos jóvenes no tienen canales de comunicación con el mundo adulto en la familia, ni en otros espacios que frecuenta como la escuela por ejemplo. Su familia asume una postura permisiva frente a todo, su madre no interferió en su elección por la música funk, viendo en ella un momento que pasaría cuando más viejo, sin creer en los resultados futuros. A pesar de las críticas a su familia, Flavinho considera que ella constituye un núcleo de protección y seguridad, cumpliendo un importante papel en su vida.

Flavinho nunca trabajó, su condición de hijo menor le permitió ese premio, siendo también una estrategia familiar para garantizar sus estudios, ya que su madre lo mantendría mientras estuviera estudiando. Así Flavinho vive la misma espectativa de muchos en la búsqueda del primer empleo, por eso, él considera sus condiciones de vida mejores que la de aquellos que ya trabajan, como su amigo funkeiro, Leo:

Acho que minha situação é melhor que a de Leo, porque posso ver os amigos todos os dias, ficar em casa, almoçar em casa, me divertir, dormir a hora que for... Nessa hora eu estou melhor, mas se for olhar a situação, depois eu acho que a minha é pior, ele pode compras as coisas dele... ${ }^{17}$

16 Yo creo que las personas de mi familia son más cerradas. No hablo mucho con ellos [con los hermanos], hablo más con mi madre... Pero mi madre no habla ni yo procuro hablar con ella sobre sexo o drogas, por ejemplo... Creo que la familia de mis amigos es más abierta, ellos se relacionan mejor... eso me parece muy bueno... en ciertos puntos la familia de ellos es mejor que la mía.

17 Yo creo que mi situación es mejor que la de Leo, porque puedo ver a mis amigos todos los días, me quedo en casa, como en casa, me divierto, duermo a la hora que quiero... En ese momento estoy mejor, pero si miro bien, mi situación es peor, él puede comprarse cosas... 
A pesar de eso, Falvinho vivía una cierta preocupación frente las posibilidades reales de encontrar algun empleo:

De vez em quando eu paro para pensar: Nó, será que um dia eu vou trabalhar? É uma coisa que vem na cabeça, assim, porque é foda, as coisas como etão aí fora... ${ }^{18}$

Pero en aquel momento, absorto con la música, con tiempo libre, sin un deseo más definido en relación a alguna ocupación, además de no sufrir ninguna exigencia familiar, él tenía todos los motivos para permanecer inerte, sin enfrentar las dificultades que es la búsqueda por trabajo. Por ahora, Flavinho desea ser un cantor de funk, soñando vivir de la actividad artística, y en esa expectativa, no alimenta otro sueño profesional. Vive intensamente su presente, no creyendo en algo que pueda cambiar su futuro, prorrogando así sus preocupaciones con su sobrevivencia.

Flavinho estudia en una escuela pública y está en el primer año de la enseñanza secundaria. Estudiar es su única actividad fija, además de eso, la escuela es la única institución donde puede tener acceso a los biense culturales y a un espacio de reflexión metódico sobre sí mismso y el mundo. A pesar de ello, la escuela no consigue cautivarle, tornándose una actividad necesaria que él apenas soporta. Además de eso, la institución no se muestra sensible a la realidad vivida por los alumnos fuera de sus muros. Flavinho se acuerda que en la escuela hay muchos funkeiros, pero cree que los profesores son contra el funk... porque ellos no saben que a todos los alumnos les gustan el funk.. yo mismo; ningun profesor sabe que escribo letras (de música funk) ni siquiera la de lengua portuguesa (lengua materna de Flavinho). Para él, la escuela posee pocos significados sobre el aspecto de espacio de socialización. Es una experiencia lejana de sus intereses, que poco contribuyen para su constitución como sujeto.

Flavinho se identifica al funk desde sus 15 años, encontrando en su estilo el sonido, las prácticas de sociabilidad y los símbolos que se tornaron referencia para estruturar una condición juvenil en la que ingresaba. La unión con los demás jóvenes del barrio, las salidas nocturnas, el visual que pasa a adoptar y principalmente la frecuencia en los bailes, son señales visibles que funcionan como mecanismos simbólicos para demarcar su identidad como joven.

18 A veces paro para pensar: ¿¿será que un día voy a trabajar? Eso es algo que viene en la cabeza así, porque es difícil, las cosas como están por ahí... 
El estilo funk posee como su epicentro los bailes, siendo en ellos donde el joven articula su identidad propia. Éste es el programa preferido de Flavinho, casi una obligación en los fines de semana. Es también en el baile que él puede expresar los demás elemento del estilo: el encuentro con los amigos, el gusto por la música funk, una determinada forma de danzar, resaltando la fiesta, la exaltación del placer y la alegía de estar juntos. Además de eso, es la oportunidad de mostrarse como MCs. Para Flavinho cantar en bailes es una emoción muy grande, siendo también una forma de hacerse conocido, principalmente en el barrio y por las niñas, además de ampliar su grupo de relaciones en el medio funk.

Es Flavinho quien escribe las letras de las canciones funk, carecterizadas por temas sobre las relaciones afectivas, la descripción de los bailes y su animación, siendo también muy común temas que tratan de situaciones ‘jocosas' ocurridas en la ciudad, además de eso, hay la exaltación de los grupos que rescatan el placer y el humor que son negados en el cotidiano de esos jóvenes. Esos temas son coherentes con el sentido que se atribuyen a sí mismos, como MCs, ser mensajero de la alegría, promoviendo la agitación de un determiado grupo de jóvenes.

En el cotidiano de Flavinho la música ocupa un lugar central, alrededor de la que invierte la mayor parte de su tiempo. Sus mañanas son cortas, pues generalmente él se despierta muy tarde, además de una u otra tarea doméstica, él pasa las tardes escuchando los programas de funk de dos emisoras de radio comunitarias de su región, en las que es común que sus músicas sean tocadas a pedido de los oyentes. Además de eso, acostumbra encontrarse con los amigos más íntimos:

Eles [os amigos] ocupam o lugar de irmão mesmo. Com eles posso conversar, se eu tô com raiva de alguma coisa, posso conversar com eles, desabafar mesmo! Isso é legal. Eles ocupam o lugar de irmão porque eu não tenho essa intimidade com meus irmãos, aí eu procuro os meus amigos. ${ }^{19}$

El punto de encuentro es casi siempre una plaza en el barrio vecino, la única de la región. Es allí que ocurren los encuentros, los

19 Ellos [los amigos] ocupan un lugar de medios hermanos mismo. Con ellos puedo charlar, si estoy con rabia de algo, puedo hablar con ellos. Desahogarme y eso se bueno. Ellos ocupan el lugar de hermano porque no tengo esa intimidad con mis hermanos, entonces, procuro mis amigos. 
noviazgos sin pretenciones más serias, los juegos o simplemente donde pasamos el tiempo. Los fines de semana son rellenados con la música, y generalmente los entrenos de la pareja son hechos los domingos, porque Leo trabaja durante la semana. Es en ese día que escuchan músicas y discuten ideas sobre las presentaciones que pretenden realizar.

El funk es el punto central alrededor del que Flavinho estrutura sus relaciones, tanto con los amigos más próximos como con los nuevos conocidos. Es la 'galera', ${ }^{20}$ se reconocen en el funk, comparten sus situaciones lúdicas, se encuentran en los bailes, principalmente en el 'Vilarinho',21 sintiéndose parte de una red simbólica (Arce, 1999). El hecho de ser un MC contribuye para ampliar esa red:

Com o funk hoje eu vivo prá fazer os outros mais felizes, e eu fiz mais amizades também e isso é legal... você tá no funk e tá rodeado de amigos. É uma diversão, mas uma coisa divertida que a gente pode levar pro futuro...22

Para Flavinho el funk no es sólo un espacio de vivencia de sociabilidades, sino también un espacio de producción de sociabilidades. Es también en los fines de semanas que Flavinho ve a su novia, lo que hace antes de ir a los bailes. Su noviazgo lleva ya más de un año, lo que significa un aprendizaje para él. Es interesante percibir el noviazgo en las diferentas etapas de las vida, para João, éste ocurre en una etapa de transición para la vida adulta, es parte integrante de un proyecto para el futuro; mientras que para Flavinho, el noviazgo es un momento de experimentaciones y decubrimiento del 'otro'. Cuando evalúa su cotidianeidad, Flavinho la clasifica como un poco vacía, monótona, diciendo que le gustaría tener más cosas para hacer:

Meu dia-a-dia é muito repetitivo. Um dia é igual ao outro. Coisas que mudam é os bailes, as músicas que eu faço, mas quando não tem nada prá fazer, o meu dia é igual ao outro... fica assim, meio vazio, porque é repetitivo, você tem de fazer as mesmas coisas porque não tem nada prá fazer...23

20 Otros jóvenes.

21 Un tipo de discoteca muy popular de la región.

22 Con el fuk hoy, vivo para hacer a otras personas felices; e hice más amistades y eso es muy bueno... Si uno está en el funk, está lleno de amigos. Es una diversión, pero algo divertido que intentamos llevar para el futuro...

23 Mi día a día es muy repetitivo. Un día es igual al otro. Lo que cambia son los bailes, las músicas que hago. Pero cuando no hay nada para hacer, mi 
En aquel momento ponía para sí mismo dos alternativas: la realización por intermedio de la música, o vivir como un trabajador pobre, en cualquier actividad que le garantice un sueldo con el que pueda sostener su familia. Frente a las incertezas propias de nuestro tiempo y de las reducidas posibilidades de una 'inserción' social más calificada, su opción es vivir el presente, con lo que éste puede ofrecerle de placer. En su caso, el sueño relacionado con la música es lo que le da sentido a su cotidiano, así como también la esperanza que siempre le apunta un rumbo, de forma de no perderse en la realidad del presente.

\section{LAS FORMAS DE SER JOVEN}

Las historias de vida de João y de Flavinho, así como nuestro contacto con otros jóvenes entrevistados, nos lleva a constatar que los estilos de música, rap y funk, constituyen un espacio y un tiempo en los que se puede afirmar la condición juvenil. Es por medio de esos estilos que ellos construyen determinados modos de ser joven. Y en esa construcción ponen en cuestión las imágenes o un cierto «modelo» de juventud.

Una primera imagen que cuestionan es la juventud vista en su dimensión de transitoriedad. Esos jóvenes muestran que vivir la juventud no es prepararse para el futuro, para un posible «venir a ser», entre otras razones porque los horizontes del futuro están cerrados. Para ellos el tiempo de la juventud es aquí y ahora por estar inmersos que están en el presente y un presente en el que se aprovecha todo lo que ofrece de diversión, de placer, de encuentros, de cambios afectivos, pero también de angustias e incertezas frente a la lucha por la sobrevivencia que se da en cada día. Eso no significa que sean pasivos o que no alimenten sus sueños y deseos, ellos los tienen, pero, con una especificidad, que casi siempre tiene como objetivo una realización en el ámbito musical y en la posibilidad de una vida más confortable, principalmente para la madre. Entretanto esos sueños y deseos necesariamente no se concretizan en proyectos de vida, y cuando lo hacen, se muestran escasos efectos o de poco alcance. Esos jóvenes se centran en el presente y a lo largo de él van contruyéndose como jóvenes, no creyendo en promesas de un futuro redentor.

día es igual al otro... Se queda así medio vacío, porque es repetitivo, uno tiene que hacer las mismas cosas porque no tiene nada que hacer... 
Otra imagen que esos jóvenes ponen en cuestión es la juventud vista como un momento de crisis y alejamiento de la familia. En el nivel de cercanía que conseguimos establecer con los rapers y funkeiros, nos fue posible constatar la existencia de conflictos familiares, pero en ningún momento ese cuadro conflictivo puso en cuestión la familia como espacio central de relaciones. Al revés, en el caso de esos jóvenes, el núcleo familiar significó un espacio de experiencias estructurantes. La relación que establecen, la calidad de cambios y los conflictos, los arreglos existentes para garantizar la sobrevivencia, los valores predominantes, son dimensiones que marcan la vida de cada uno, constituyéndose en un filtro por el que traducen el mundo social y donde inicialmente descubren su lugar en él (Sarti, 1996, 1999).

Esas experiencias familiares vienen a poner en cuestión una imagen muy difundida sobre las familias de las camadas populares, observadas según el punto de vista de la estructuración X la desestructuración, en la que el criterio de defnición es el modelo de familia como célula central, formada por padre, madre e hijos. Los datos, en el mínimo, problematizan esa imagen. La mayoría de las familia de esos jóvenes no cuentan con la figura paterna, organizándose en términos matriarcales y no por eso se muestran 'desestructuradas', garantizando, con esfuerzo, la reprodución física y moral del núcleo doméstico. Más importante que la presencia o no del padre, lo que parece definir el grado de estructuración familiar, es la calidad de las relaciones con las que pueden contar.Y en eso, la madre desempeña un papel fundamental. Es ella la referencia del cariño, de autoridad y de los valores, para quien es direccionada la obligación moral de la retribución. Tanto es verdad, que todos desean en sus proyectos de futuro, ofrecer a la madre una vida más confortable.

Otra imagen que los jóvenes ponen en cuestión es la de la juventud como un momento de crisis personal. En lo que nos fue posible observar, no evidenciamos la existencia de crisis en la llegada de la juventud, menos aun, señales de conflictos atribuidos típicamente a los adolescentes. Si existe una crisis, ésta fue constatada en el pasaje para la vida adulta. La imagen del adulto que ellos construyen es muy negativa. Ser adulto es estar obligado a trabajar para sustentar a la familia, ganar poco, en la lógica del trabajo subalterno. Pero es también asumir un postura séria, disminuyendo los espacios y tiempos de encuentro, con una moral basada en valores más rígidos, abriendo mano de la fiesta, de la alegría y de las emociones que vivenciaban. 
Para muchos, ser adultos, significa dejar su estilo de vida actual, haciendo de ese pasaje un momento de dudas y angustias, vivido siempre como problemático. No que recusen o nieguen este pasaje, pero la vivencian como una crisis, y una crisis vivida, no en la entrada de la juventd, sino en su salida.

Finalmente la trayectoria de esos jóvenes cuestionan la visión romántica de la juventud. La realidad de los rappers y funkeiros investigados deja claro que la juventud para ellos no corresponde a esta imagen. Al revés, es un momento lleno de dificultades concretas de sobrevivencia, de tensiones con la instituciones como el trabajo y la escuela. La realidad del trabajo aparece de forma dura, expresión de la crisis de la sociedad asalariada que afecta principalmente a los jóvenes pobres.

La relación de esos jóvenes con el mercado del trabajo expresa una lógica presente en la sociedad brasileña contemporánea, que, según Martins (1997:3), crea un grupo de personas con muy pocas chances de «ser» de verdad, reintroducida en los patrones actuales de desarrollo económico. Aún según Martin, el período del pasaje del momento de la exclusión para el momento de la inclusión, está transformándose en una forma de vida, está tornándose cada vez más que un momento de transición.

Viviendo de 'bicos' (trabajos informales) la mayoría de ellos cree en la posibilidad de sobrevivir de la actividad artística o, por lo menos, de un trabajo que esté de alguna forma unido a alguna actividad cultural. El trabajo aparece como una obligación necesaria, pero que a su vez dificulta las actividaes musicales, por ahora sueñan con un trabajo expresivo, en el que puedan realizarse personalmente. Esa postura puede ser encarada como una recusa, aunque provisoria, de las condiciones que la sociedad les ofrece para su inserción social. De igual modo, aquellos que aún viven las incertidumbres del primer empleo, como Flavinho, se muestran inclédulos de lo que el mundo del trabajo pueda ofrecerles.

Podemos decir que el mundo del trabajo poco contribuyó en el proceso de humanización de esos jóvenes, no abriendo para ellos perspectivas para que pudieran ampliar sus potencialidades, todavía menos para que pudieran construir una imagen positiva de sí mismos. Es uno de los espacios del mundo adulto que se revela impermeable a las necesidades de los jóvenes en construirse como sujetos.

Con todo, las experiencias de esos jóvenes deja claro que la institución escuela se encuentra lejana de sus intereses y necesidades, 
no consiguiendo entender ni responder a las demandas que les son puestas, poco contribuyendo en su construcción como sujetos. Al fin y al cabo, esos jóvenes expresan un contexto de una nueva desigualdad social en una sociedad que apenas les abre perspectivas frágiles e insuficientes de inclusión (Martins, 1997).

En esos contexto, los estilos rap o funk, aunque de forma diferenciadas, significan una fuerte referencia en la elaboración y en la vivencia juvenil. Para todos significó una ampliación de los circuitos y redes de cambios, tornándose el medio privilegiado por el que se introducieron en la esfera pública. Por las facilidades de aquellas relaciones y en las actividades de diversión, esos jóvenes fueron construyendo formas de sociabilización propias, en un ejercicio de convivencia social, aprendiendo a convivir con las diferencias. La vivencia del estilo musical posibilitó a esos jóvenes, prácticas, relaciones y símbolos por los que se afirmaron con una identificación propia como jóvenes. Concluyendo, el estilo se encuentra como mediador de una determinada forma de ser joven.

Podemos decir que por medio del rap o del funk, los jóvenes experimentan la posibillidad de alargar el tiempo de la juventud lo máximo que puedan, así como una 'moratoria'. El sentido de ese comportamiento no es una huelga del ingreso en la vida social adulta, o de irresponsabilidad como se piensa, sino una forma de garantizar espacios de experiencias y aprendizajes de la vida, de no ser tan exigidos por los demás, de permitirse una relación más libre con el trabajo, de invertir tiempo en la sociedad y en los cambios afectivos. Es en el envolvimiento con el rap o con el funk que se crea, posibilita y legitima la moratoria como una experiencia validada.

Mientras tanto el estilo rap o funk posibilita a muchos de esos jóvenes una ampliación significativa de hipótesis de vida (Giddens, 1995), abriendo espacios para soñar con otras alternativas de vida diferentes de las ofrecidas por la sociedad. Pero las perspectivas son muy pocas. En realidad esos estilos poseen límites, no respondiendo a las cuestiones centrales como: la profesionalización y la sobrevivencia, principalmente en el momento de ingresar en la vida adulta. Muchos de ellos, como João, aunque un poco más viejos (mayores) y con compromisos familiares, como el noviazgo (de Joao), siguen insistiendo en mantener el estilo joven.

Entretanto, la mayoría desiste por ser obligados a abandonar el sueño con la carrera musical por no conseguir mantenerla debido a las necesidades de sobrevivencia. De esta forma el estilo rap o funk se 
convierte en una opción pasajera, aunque sea más larga para algunos de ellos. Para la mayoría de esos jóvenes, la experiencia de la juventud es muy intensa, pero corta. Podemos observar que los rappers y funkeiros parecen reconstruir las imágenes de la juventud, creando formas propias de ser joven, siempre basados en el estilo (rap o funk).

En un contexto de transformaciones socioculturales más amplias por las que pasa Brasil, parecen surgir nuevos sitios en el mundo juvenil, casi siempre unidos a la cultura. Este mundo cultural se presenta más democrático, posibilitando espacios, tiempos y experiencias que les permite construirse como sujetos. Sin embargo, no podemos olvidar que en Brasil la modernización cultural, que tanto influencia la vida de esos jóvenes, no es seguida por la modernización social. Con eso, si la cultura se presenta como un espacio más abierto es por que los demás espacios están cerrados para esos jóvenes. Con eso no podemos caer en una postura ingenua de una supervaloración del mundo cultural como el que posibilita la salvación o solución de los problemas y desafíos vividos por los jóvenes pobres. En el contexto donde viven, ninguna institución, sea la escuela, el trabajo o aquella unida a la cultura, poco pueden hacer si no están basadas en una red de sustentación más amplia y con políticas publicas que garanticen espacios y tiempo para que esos jóvenes puedan construirse como sujetos y ciudadanos, con derecho a vivir plenamente su juventud.

BELO HORIZONTE, MARZO 2003

\section{REFERENCIAS BIBLIOGRÁFICAS}

Abramo, Helena (1994): Cenas juvenis. Punks e darks no espetáculo urbano. São Paulo: Escrita.

ABROMAVAY, MiRIAM et al. (1999): Gangues, galeras, cegadas $e$ rappers, juventude, violência e cidadania nas cidades da periferia de Brasília. Rio de Janeiro: Garamond.

ANDRADE, ELAINE (1996): Movimento negro juvenil. Um estudo de caso sobre jovens rappers de São Bernardo do Campo. São Paulo: Faculdade de Educação da USP (dissertação mestrado).

ARCE, José MANuel VAlenzuela (1999): Vida de barro duro. Cultura popular juvenil e grafite. Rio de Janeiro: Editora UFRJ.

CECHETTO, FÁTIMA REGINA (1997): Galeras funk cariocas. O baile e 
a rixa. Rio de Janeiro: Departamento de Ciências Sociais, UFRJ (dissertação mestrado).

CHARLOT, BERNARD (2000): Da relação com o saber. Elementos para uma teoria. Porto Alegre: Artemed Editora.

COSTA, MARIA Regina (1993): Os carecas de subúrbio: caminhos de um nomadismo moderno. Petrópolis: Vozes.

DAYRELL, JUAREZ (1996): Múltiplos olhares sobre educação e cultura. Belo Horizonte: Editora UFMG.

(1999): «Juventude, grupos de estilo e identidades». Educação em Revista $\mathrm{N}^{\circ} 30$. Belo Horizonte.

- (2001): «A música entra em cena: o rap e o funk na socialização da juventude em Belo Horizonte». São Paulo: Faculdade de Educação (tese doutorado).

(2002a): «O rap e o funk na socialização da juventude». Educação e Pesquisa V. 28, Nº1. São Paulo.

(2002b): «Juventude, produção cultural e a escola». Caderno do Professor $N^{\circ} 9$. Belo Horizonte: Secretaria Estadual de Educação de MG.

FEIXA, CARLOS (1998): De jóvenes, bandas y tribus. Barcelona: Ariel.

GIDDENS, ANTHONY (1995): Modernidad e identidad del yo. El yo y la sociedad en la época contemporánea. Barcelona: Ediciones Península.

GUERREIRO, GOLI (1994): Retratos de uma tribo urbana: rock brasileiro. Salvador: Centro Editorial e Didático da UFBA.

GUIMARÃES, MARIA ELOÍSA (1995): Escola, galeras e narcotráfico. Rio de Janeiro: Departamento de Educação PUC-RJ (tese doutorado).

HERSCHMANN, MicAEL (2000): O funk e o hip hop invadem a cena. Rio de Janeiro: Editora UFRJ.

KEMP, KENIA (1993): «Grupos de estilo jovens. O rock underground e as práticas (contra) culturais dos grupos 'punk' e 'trash' em São Paulo». São Paulo: Departamento de Antropologia da UNICAMP (dissertação mestrado).

LECCARDI, CARMEM (1991): Orizzonte del tempo. Esperienza del tempo e mutamento sociale. Milano: Franco Angeli.

MARTINS, JosÉ DE SOUZA (1997): Exclusão social e a nova desigualdade. São Paulo: Paulus.

MELUCCI, AlBERTO e ANNA FABRINI (1992): L'età dell'oro: adolescenti tra sogno ed esperienza. Milano: Feltrinelli.

MORCELLINI, MARIO (1997): Passagio al futuro, formazione e socia- 
llizzazione tra vecchi e nuovi media. Milão: Franco Angeli.

PAIS, JosÉ MACHADO (1993): Culturas juvenis. Lisboa: Imprensa Nacional Casa da Moeda.

Peralva, Angelina (1997): «O jovem como modelo cultural». Revista Brasileira de Educação Nº5/6. São Paulo: ANPED.

SALEM, TÂNIA (1986): «Filhos do Milagre». Ciência Hoje V. 5, №25. SBPC.

SARTI, CYNTHIA (1996): A família como espelho. Um estudo sobre a moral dos pobres. Campinas: Autores Associados. (1999): «Família e jovens no horizonte das ações». Revista Brasileira de Educação Nº11. São Paulo.

SILVA, José CARLOS GOMES (1998): «Rap na cidade de São Paulo: música, etnicidade e experiência urbana». Campinas: Departamento de Ciências Sociais do Instituto de Filosofia e Ciências Humanas da UNICAMP (tese doutorado em ciências sócias).

SPOSITO, MARÍLIA (1993): «A sociedade juvenil e a rua; novos conflitos e ação coletiva na cidade». Tempo Social, Revista Sociologia da USP V. 5, Nº1/2. São Paulo: USP. (2000): Estado do conhecimento: juventude. Brasília: INEP.

Tella, MARCo Aurélio PAZ (2000): «Atitude, arte, cultura e autoconhecimento. O rap como voz da periferia». São Paulo: Departamento de Ciências Sociais da PUC-SP (dissertação mestrado).

ViAnNA, HERMANO (1987): O mundo funk carioca. Rio de Janeiro: Jorge Zahar.

- (1997) (Org.): Galeras cariocas, territórios de conflitos e encontros culturais. Rio de Janeiro: Editora da UFRJ.

ZALUAR, ALBA (1997): «Gangues, galeras e quadrilhas: globalização, juventude e violência». In HERMANO VIANNA (Org.): Galeras cariocas, territórios de conflitos e encontros culturais. Rio de Janeiro: Editora da UFRJ. 